\title{
A New Fluoride Chemodosimeter Based On 3-Ether- Substituted 1, 8-Naphthalimide Derivatives
}

\section{Xi Chen}

Shanghai Institute of Technology

\section{Haibing Shao}

Shanghai Institute of Technology

\section{Tingting Zhu}

Shanghai Institute of Technology

\section{Zhihua Chen}

Shanghai Institute of Technology

\section{Yan $\mathrm{Hu}$}

Shanghai Institute of Technology

\section{Hua Zhang}

Shanghai Institute of Technology

Chuanxiang Liu ( $\nabla$ cxliu@sit.edu.cn )

Shanghai Institute of Technology https://orcid.org/0000-0002-4340-0667

\section{Research Article}

Keywords: colorimetric, fluorescence, chemodosimeter, fluoride ion, 1,8-naphthalimide

Posted Date: September 20th, 2021

DOI: https://doi.org/10.21203/rs.3.rs-836586/v1

License: (c) (i) This work is licensed under a Creative Commons Attribution 4.0 International License.

Read Full License 


\section{Abstract}

We developed a new chromogenic and fluorescent "off-on" 1,8-naphthalimide-derivated chemosensor 1 based on an $\mathrm{F}^{-}$-triggered desilylation reaction. It showed significant variations in UV/Visible absorption $(510 \mathrm{~nm})$ and fluorescence emission wavelength $(570 \mathrm{~nm})$ for selective detection of fluorides in tetrahydrofuran. Moreover, chemodosimeter 1-loaded test strips were successfully fabricated todetect fluorides efficiently.

\section{Research Highlights}

\section{A new sensor based on an F-triggered desilylation reaction}

2. The test strips loaded probe 1 exhibited efficiently detection of fluorides with significant changes in fluorescence.

\section{Introduction}

Fluoride ions widely exist in the nature and organisms, and play an extremely important role in the metabolic process of organisms. It is widely used in dental treatment, disease surveillance, and drinking water health control ${ }^{[1-4]}$. Excessive fluoride ions leakage not only pollute the environment, but also cause irreversible harm to physiological condition, such as dental fluorosis, skeletal fluorosis, the acute reaction of gastrointestinal, and nephrotoxic lesions ${ }^{[5-6]}$. Therefore, the development of new chemodosimeter to detect fluoride ions has attracted wide attention.

Among various fluorine ion detection technologies, the fluorescence method has been widely used in food detection, environmental monitoring, cell imaging, and other fields due to its high selectivity, rapid response, and strong anti-interference. Many sensor systems for fluoride detection have been developed to date for the detection of fluoride ions, including metal ion coordination ${ }^{[7-8]}$, Lewis acid base ${ }^{[9-10]}$, hydrogen bond ${ }^{[11-15]}$, and silicon-carbon bond cleavage ${ }^{[16-17]}$ sensing mechanisms.

School of Chemical and Environmental Engineering, Shanghai Institute of Technology, 201418 Shanghai, P. R. China

The fluorescent sensor based on fluoride-induced desilylation reaction has attracted much attention. Especially, those fluorophore have been investigated extensively such as the skeleton of BODIPY, coumarin, and 1,8-naphthalimide derivatives ${ }^{[18-20]}$. However, in contrast to those probes for detection of fluoride, the chemodosimeter based on fluoride-induced desilylation reaction showing long wavelength response is limited (TableS1) ${ }^{[21-24]}$. In view of fluorescent probes with long emission wavelength have low light damage, low self-fluorescence as well as the better deep tissue penetration ${ }^{[25-28]}$, it is very important to develop a new fluorescent chemodosimeter with the advantage of potential longer emission wavelength triggered by fluorine-induced desilylation reaction. 
1,8-naphthalimide fluorophore has a rigid planar skeleton and a large $\pi$-conjugated system, which can be used as a good chromophore. One particularly intriguing approach is based on the construction of a donor-acceptor-type skeleton that introduces the binding site such as $\mathrm{OH}$ or $\mathrm{NH}$ group in the 4-position of 1, 8-naphthalimide derivatives. However, the 3-substituted 1, 8-naphthalimide derivatives as sensor are less investigated. Here, we reported a new colorimetric and fluorescent chemodosimeter 1 coupled with 4(tert-butyldiphenylsilyloxy)benzylbromide (3) and 3-hydroxy-4-cyano-1,8-naphthalimide (2). The chemodosimeter showed significant color and fluorescent changes, highly selectivity and long wavelength response through the classical fluoride-induced desilylation reaction.

\section{Experimental}

\section{General information}

Unless otherwise noted, solvents and reagents were choosed and purchased from commercial channels. They were analytical reagents that can be directly used. The column chromatography using silica gel (200-300 sights) was performed. The intermediate 2 was synthesized according to the reported literature. We used SHIMADZU UV-1800 spectrophotometer to determine UV-visible absorption spectra. We used the Hitach F-4600 Fluorescence spectrophotometer to determine the fluorescence emission spectra. We used Bruker AVANCE III instrument to obtain the ${ }^{1} \mathrm{H}$ NMR and ${ }^{13} \mathrm{C}$ NMR spectra. Mass spectra analyses were performed on SolanX 70 FT-MS electrospray ionization high-resolution mass spectra.

\section{Synthesis of probe 1}

The synthesis of target chemodosimeter 1 is shown in Scheme 1. The intermediates 3-hydroxy-4-cyano1,8-naphthaleneimide (2) and 4-(tert-Butyldiphenylsilyloxy)benzylbromide (3) were synthesized according to the literature ${ }^{[29-30]}$. To a solution of 3-hydroxy-4-cyano-1, 8-naphthaleneimide $(2,0.20 \mathrm{~g}, 0.68 \mathrm{mmol})$ in $\mathrm{CH}_{3} \mathrm{CN}(20 \mathrm{~mL})$ was added 3.0 equiv. of potassium carbonate $(0.28 \mathrm{~g}, 2.04 \mathrm{mmol})$, and the mixture was stirred at $50^{\circ} \mathrm{C}$ for $1 \mathrm{~h}$. After adding 3.0 equiv. of 4-(tert-Butyldiphenylsilyloxy)benzylbromide $(3,0.87 \mathrm{~g}$, $2.04 \mathrm{mmol}$ ), then the mixture was further refluxed for $24 \mathrm{~h}$. After cooling of the reaction mixture, the residue was poured into dilute hydrochloric acid, and then extracted with ethyl acetate $(20 \mathrm{~mL} \times 3)$, then the organic layer was further washed with brine, then dried with $\mathrm{Na}_{2} \mathrm{SO}_{4}$ and filtered. After the removal of solvent in vacuo, the residue was purified by chromatography (PE:EA = 10:1) to afford the probe $1(0.21 \mathrm{~g}$, $48 \%)$ as a white solid. ${ }^{1} \mathrm{H} \mathrm{NMR}\left(500 \mathrm{MHz}, \mathrm{CDCl}_{3}\right) \delta 8.51(\mathrm{~d}, J=7.0 \mathrm{~Hz}, 1 \mathrm{H}), 8.40(\mathrm{~d}, J=8.5 \mathrm{~Hz}, 1 \mathrm{H}), 8.34$ $(\mathrm{s}, 1 \mathrm{H}), 7.88(\mathrm{t}, J=8.0 \mathrm{~Hz}, 1 \mathrm{H}), 7.70(\mathrm{~d}, J=7.0 \mathrm{~Hz}, 4 \mathrm{H}), 7.41(\mathrm{t}, J=7.0 \mathrm{~Hz}, 2 \mathrm{H}), 7.36(\mathrm{t}, J=7.0 \mathrm{~Hz}, 4 \mathrm{H})$, $7.24(\mathrm{~s}, 2 \mathrm{H}), 6.80$ (d, J=8.0 Hz, $2 \mathrm{H}), 5.34$ (s, $2 \mathrm{H}), 4.16$ (t, J= $7.5 \mathrm{~Hz}, 2 \mathrm{H}), 1.72-1.66(\mathrm{~m}, 2 \mathrm{H}), 1.09$ (s, 9 H), 0.98 (t, J= 7.5 Hz, $3 \mathrm{H}), 0.89-0.82(\mathrm{~m}, 2 \mathrm{H}) ;{ }^{13} \mathrm{C} \mathrm{NMR}\left(125 \mathrm{MHz}, \mathrm{CDCl}_{3}\right) \delta 163.3,162.8,160.8,156.1$, 135.6, 132.7, 132.7, 130.1, 123.0, 129.9, 129.9, 129.8, 128.9, 127.9, 127.8, 127.6, 127.2, 123.0, 122.9, $120.2,119.8,117.3,114.2,101.4,71.8,40.7,30.2,27.0,26.6,20.4,19.5,13.9 ;$ HRMS-ESI (m/z): $\left[\mathrm{M}+\mathrm{H}^{+}\right.$ Calcd. for $\left(\mathrm{C}_{40} \mathrm{H}_{38} \mathrm{~N}_{2} \mathrm{O}_{4} \mathrm{Si}\right): 639.2674$; Found:639.2680. 


\section{Results And Discussion}

\section{Sensing property of probe 1 for fluoride ions}

Initially, the selectivity of chemodosimeter 1 was evaluated by measuring the changes of absorption spectra after the addition of different anions (Fig. 1). Only the addition of fluorideions (1.8 equiv., TBAF), the new absorption peak at $510 \mathrm{~nm}$ was increased followed by the unique color change from colorless to yellow, indicating that fluoride-induced desilylation reaction take places and the potential 3-hydroxy-4cyano-1,8-naphthaleneimide was produced. However, the introduction of other anions, such as $\mathrm{CN}^{-}, \mathrm{AcO}^{-}$, $\mathrm{H}_{2} \mathrm{PO}_{4}{ }^{-}, \mathrm{I}^{-}, \mathrm{Cl}^{-}, \mathrm{NO}_{3}{ }^{-}, \mathrm{HSO}_{4}{ }^{-}, \mathrm{ClO}_{4}{ }^{-}, \mathrm{BF}_{4}{ }^{-}, \mathrm{Br}^{-}, \mathrm{SCN}^{-}, \mathrm{S}^{2-}, \mathrm{GSH}, \mathrm{OH}^{-}$ions (as their TBA salts) did not result in significant difference in color change, indicating the chemodosimeter $\mathbf{1}$ has the high selectivity for $\mathrm{F}^{-}$. Next, with further increase of fluorine ion concentration, a significant color change from colorless to yellow was observed (Fig. 2, inset), and followed by the absorption peak at 345 and $390 \mathrm{~nm}$ decreases and a remarkable increase of new peaks at 273 and $510 \mathrm{~nm}$. Three isotonic points appeared at $320 \mathrm{~nm}$, $356 \mathrm{~nm}$ and $410 \mathrm{~nm}$ in THF (Fig. 2). In order to demonstrate the application of chemodosimeter 1 in water-containing conditions, similar UV-vistitrations were carried out in $\mathrm{THF} / \mathrm{H}_{2} \mathrm{O}$ system (Fig.S5), and similar spectral responses were generated, but in the presence of excessive fluoride ions. It indicates that probe 1 is less effective in aqueous environments.

The most significant changes were observed in fluorescence titration studies. Upon excitation at $410 \mathrm{~nm}$ in THF, with the addition of $\mathrm{F}^{-}$, probe 1 showed strong emission at $570 \mathrm{~nm}$ (Fig. 3). However, the introduction of other anions, such as $\mathrm{F}^{-}, \mathrm{CN}^{-}, \mathrm{AcO}^{-}, \mathrm{H}_{2} \mathrm{PO}_{4}{ }^{-}, \mathrm{I}^{-}, \mathrm{Cl}^{-}, \mathrm{NO}_{3}{ }^{-}, \mathrm{HSO}_{4}{ }^{-}, \mathrm{ClO}_{4}{ }^{-}, \mathrm{BF}_{4}{ }^{-}, \mathrm{Br}^{-}, \mathrm{OH}^{-}$ ions (as their TBA salt ), did result in no change in the emission intensity of probe 1 (Fig. 4). The unique orange fluorescence emission induced by fluorides was observed, which further showed the excellent selectivity of probe 1 for fluoride ions. In addition, this selectivity of probe $\mathbf{1}$ was further confirmed by competitive experiments (Fig. 5). The unique absorption and fluorescence bands produced by adding fluoride ions were not affected by other existing anions (including $\mathrm{CN}^{-}, \mathrm{AcO}^{-}, \mathrm{H}_{2} \mathrm{PO}_{4}{ }^{-}, \mathrm{I}^{-}, \mathrm{Cl}^{-}, \mathrm{NO}_{3}{ }^{-}$, $\left.\mathrm{HSO}_{4}{ }^{-}, \mathrm{ClO}_{4}{ }^{-}, \mathrm{BF}_{4}{ }^{-}, \mathrm{Br}^{-}, \mathrm{OH}^{-}\right)$. The fluorescence detection limit of probe 1 was further determined to be $1.16 \mu \mathrm{M}$ (Fig. S6).

In addition, to further demonstrate the practicability of this sensor, the test paper were prepared by immersing the test paper into THF solution of $1(1.0 \mathrm{mM})$ and drying them in air. As shown in Fig. 6 , the probe 1-loaded test paper with can be used as a 'life monitor' to detect $\mathrm{F}^{-}$in the solution with significant color changes in fluorescence. This application provides a strong basis for further development of sensors similar to 'life monitor' method.

\section{Possible reaction mechanism of probe 1 with fluorine ions}

In order to confirm the sensing mechanism, the titration reaction of chemodosimeter 1 with $\mathrm{F}^{-}$was analyzed by ${ }^{1} \mathrm{H}$ NMR spectra. ${ }^{1} \mathrm{H}$ NMR spectra confirmed that compound 2 was obtained by treating compound 1 with fluoride ions (Fig. S8). The results showed that compound 1 could react with fluorine 
ions to generate the compound 2 by the classical desilylation reaction (Scheme 2). Therefore, a new colorimetric and fluorescent 3-hydroxy-4-cyano-1,8-naphthaleneimide-based probe 1 by the fluorinetriggered desilylation reaction was developed for the first time.

\section{Conclusion}

In general, a new and simply chemosensor $\mathbf{1}$ based on fluorine-triggered desilylation reaction was described, and the mechanism involving the cascade release reaction to obtain the fluorophore of 3hydroxy-4-cyano-1,8-naphthaleneimide were studied. The probe 1 was shown excellent selectivity and sensibility to fluoride ions with significant dual changes in UV/vis and fluorescence spectra in aqueous THF solution. Significantly, the probe 1-based test strips was successfully prepared and exhibited efficiently detection of fluorides with significant changes in fluorescence. Further work on this framework with 3-hydroxy-4-cyano-1,8-naphthaleneimide working in the aqueous solution is expected to yield novel fluoride-sensing probe with practical utility.

\section{Declarations}

\section{Acknowledgements}

We thank the Natural Science Foundation of Shanghai (No. 17ZR1429900) and the Opening Fund of Shanghai Key Laboratory of Chemical Biology for financial support.

\section{Funding}

The Natural Science Foundation of Shanghai (No. 17ZR1429900) and the Opening Fund of Shanghai Key Laboratory of Chemical Biology.

\section{Author Contributions}

All authors contributed to the study conception and design. Xi Chen carried out the experiments, Haibin Shao, Tingting Zhu, Zhihua Chen and Yan Hu conducted the data analyses, Hua Zhang and Chuanxiang Liu wrote and edited the paper.

\section{Data Availability}

Not applicable.

\section{Code Availability}

Not applicable.

\section{Author information}

\section{Consent to Participate}


Not Applicable.

\section{Consent for Publication}

Not Applicable.

\section{Conflicts of interest}

There are no conflicts of interest to declare.

\section{Ethics Approval}

Not Applicable.

\section{References}

1. Zhou Y, Zhang JF, Yoon J (2014) Fluorescence and colorimetric chemosensors for fluoride-ion detection. Chem Rev 114:5511-5571

2. Craig L, Lutz A, Berry KA, Yang W (2015) Recommendations for fluoride limits in drinking water based on estimated daily fluoride intake in the Upper East Region, Ghana. Sci Total Environ 532:127-137

3. Zhang LE, Huang D, Yang J (2017) Probabilistic risk assessment of Chinese residents' exposure to fluoride in improved drinking water in endemic fluorosis areas. Environ Pollut 222:118-125

4. Lin YJ, Lin C, Yeh KJ, Lee A (2000) Photodegradation of the Herbicides Butachlor and Ronstar Using Natural Sunlight and Diethylamine. Bulletin of Environmental Contamination Toxicology 64(6):780785

5. Perumal E, Paul V, Govindarajan V, Panneerselvam L (2013) A brief review on experimental fluorosis. Toxicol Lett 223(2):236-251

6. Yu X, Chen J, Li Y (2018) Threshold effects of moderately excessive fluoride exposure on children's health: A potential association between dental fluorosis and loss of excellent intelligence. Environ Int 118:116-124

7. Ding W-H, Wang D, Zheng X-J (2015) A turn-on fluorescence chemosensor for $\mathrm{Al}^{3+}, \mathrm{F}^{-}$and $\mathrm{CN}^{-}$ions, and its application in cell imaging. Sensors Actuators B: Chemical 209:359-367

8. Diao Q, Ma P, Lv L (2016) A water-soluble and reversible fluorescent probe for $\mathrm{Al}^{3+}$ and $\mathrm{F}^{-}$in living cells. Sensors Actuators B: Chemical 229:138-144

9. Kim Y, Gabbaie FP (2009) Cationic Boranes for the Complexation of Fluoride lons in Water below the 4 ppm Maximum Contaminant Level. J Am Chem Soc 131:3363-3369

10. Rosen CB, Hansen DJ, Gothelf KV (2013) Efficient colorimetric and fluorescent detection of fluoride in DMSO-water mixtures with arylaldoximes. Org Biomol Chem 11:7916-7922

11. Peng XJ, Wu YK, Fan JL, Tian MZ, Han KL (2005) Colorimetric and ratiometric fluorescence sensing of fluoride: Tuning selectivity in proton transfer. J Org Chem 70:10524-10531 
12. Madhu S, Ravikanth M (2014) Boron-dipyrromethene based reversible and reusable selective chemosensor for fluoride detection. Inorg Chem 53:1646-1653

13. Renuga D, Udhayakumari D, Suganya S, Velmathi S (2012) Novel thiophene based colorimetric and fluorescent receptor for selective recognition of fluoride ions. Tetrahedron Letters 53:5068-5070

14. Chen J, Liu C, Zhang J, Ding W, Zhou M, Wu F (2013) A novel chemodosimeter for fluoride ions based on deprotonation of the $\mathrm{C}-\mathrm{H}$ group followed by an autoxidative decyanation process. Chem Commun 49:10814-10816

15. Zhou M, Chen J, Liu C (2014) Anion binding modes in cis-trans-isomers of a binding site-fluorophorepi-extended system. Chem Commun 50:14748-14751

16. Fu L, Jiang FL, Fortin D, Harvey PD, Liu Y (2011) A reaction-based chromogenic and fluorescent chemodosimeter for fluoride anions. Chem Commun 47:5503-5505

17. Buckland D, Bhosale SV, Langford SJ (2011) A chemodosimer based on a core-substituted naphthalene diimide for fluoride ion detection. Tetrahedron Letters 52:1990-1992

18. Zhou J, Wu B, Zhou Z, Tian J, Yuan A(2019) A Novel Naphthalene-Fused Boron Dipyrromethene (BODIPY)-Based Near Infrared Fluorescent Probe for Detecting Fluoride in Living Cells. Chinese Journal of Organic Chemistry. 39

19. Ji K, Wu H, Chen J (2016) A selective chromofluorogenic chemodosimeter for fluoride ions based on distyrylbenzenes derivatives containing dual Si-O groups. Luminescence 31:924-928

20. Ren J, Wu Z, Zhou Y, Li Y, Xu Z (2011) Colorimetric fluoride sensor based on 1,8-naphthalimide derivatives. Dyes Pigments 91:442-445

21. Hu Q, Huang Q, Mao Y (2019) A near-infrared large Stokes shift probe based enhanced ICT strategy for $\mathrm{F}^{-}$detection in real samples and cell imaging. Tetrahedron 75:130762

22. Li B, Zhang C, Wang Y (2015) Chromogenic and fluorescent 'turn-on' chemodosimeter for fluoride based on a $F()$-triggered cascade reaction. Luminescence 30:699-702

23. Shi J, Shu W, Wu Y, Jing J, Zhang R, Zhang X (2019) A highly colorimetric and ratiometric fluorescent probe for the detection of fluoride ions using test strips. Analytical Methods 11:3844-3850

24. Liu C, Liu Z, Zhu T, Fu C, Gao C, Chen X (2021) Synthesis and Recognition Properties of Fluoroborodipyrrole Fluorescent Probes Based on Fluorine Triggered Cascade Releasing. Chinese Journal of Organic Chemistry 41:303-309

25. Cheng $W$, Xue $X$, Gan $L$ (2021) Individual and successive detection of $\mathrm{H}_{2} \mathrm{~S}$ and $\mathrm{HClO}$ in living cells and zebrafish by a dual-channel fluorescent probe with longer emission wavelength. Anal Chim Acta 1156:338362

26. Zhong K, Hu X, Zhou S (2021) Mitochondria-Targeted Red-Emission Fluorescent Probe for Ultrafast Detection of $\mathrm{H}_{2} \mathrm{~S}$ in Food and Its Bioimaging Application. J Agric Food Chem 69:4628-4634

27. Wang WX, Jiang WL, Mao GJ (2021) Monitoring the Fluctuation of Hydrogen Peroxide in Diabetes and Its Complications with a Novel Near-Infrared Fluorescent Probe. Anal Chem 93:3301-3307 
28. Luo X, Cheng Z, Wang R, Yu F (2021) Indication of Dynamic Peroxynitrite Fluctuations in the Rat Epilepsy Model with a Near-Infrared Two-Photon Fluorescent Probe. Anal Chem 93:2490-2499 29. Pettit GR, Grealish MP, Jung MK (2002) Antineoplastic Agents. 465. Structural Modification of Resveratrol: SodiumResverastatin Phosphate. J MedChem 45:2534-2542

30. Chen L, Fu C, Li Z (2020) A new strategy for sensing cyanide ions by cyanide-induced nucleophilic substitution of hydrogen in nitro-controlled electron-deficient fluorophores. Tetrahedron Letters $61: 151656$

\section{Figures}

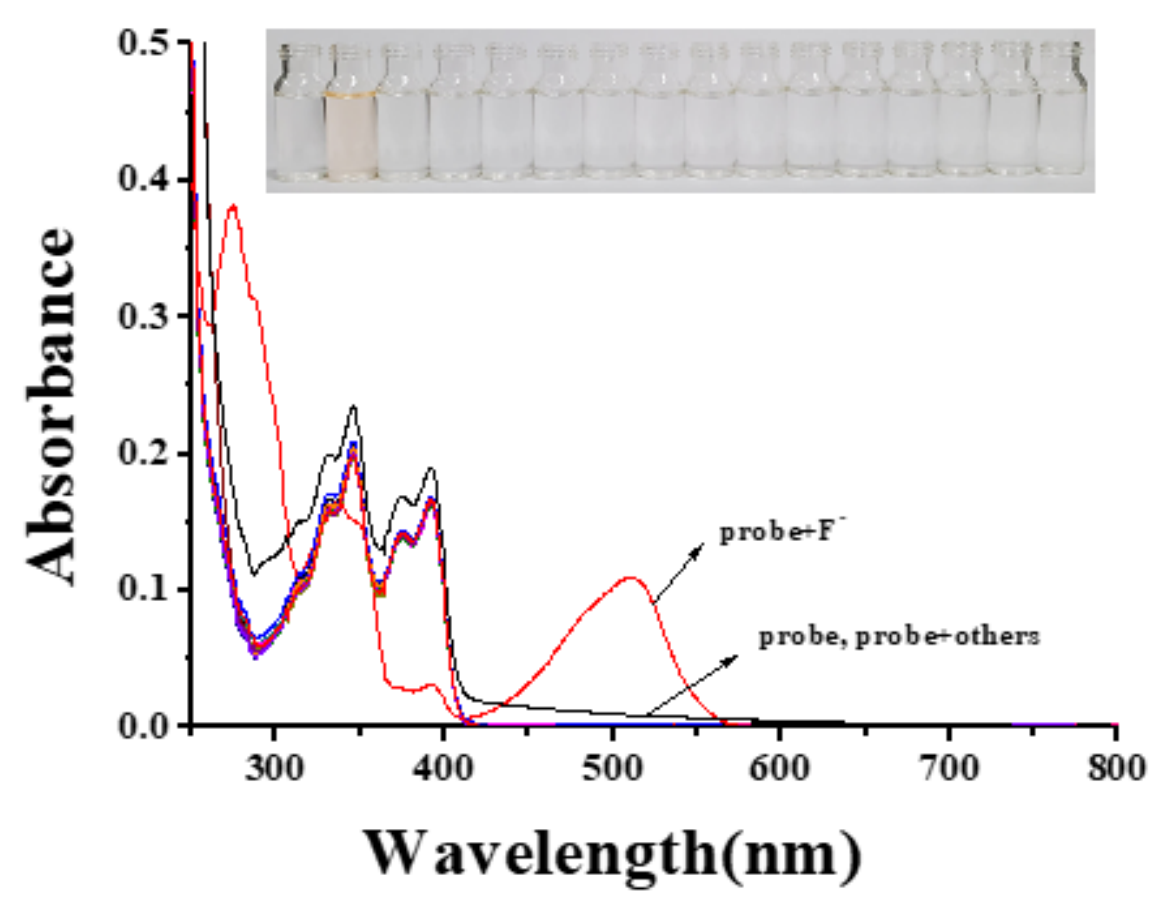

Figure 1

Absorption spectra responses of probe $1(20 \mu \mathrm{M})$ in THF with various anions (ca. 1.8 equiv.) (Inset: color changes of 1 from left to right: probe 1 only, $\mathrm{F}-, \mathrm{CN}-, \mathrm{AcO}-, \mathrm{H} 2 \mathrm{PO} 4-, \mathrm{I}-, \mathrm{Cl}-, \mathrm{NO} 3-$, HSO4-, ClO4-, BF4,Br-, SCN-, S2-, GSH ,OH-. 


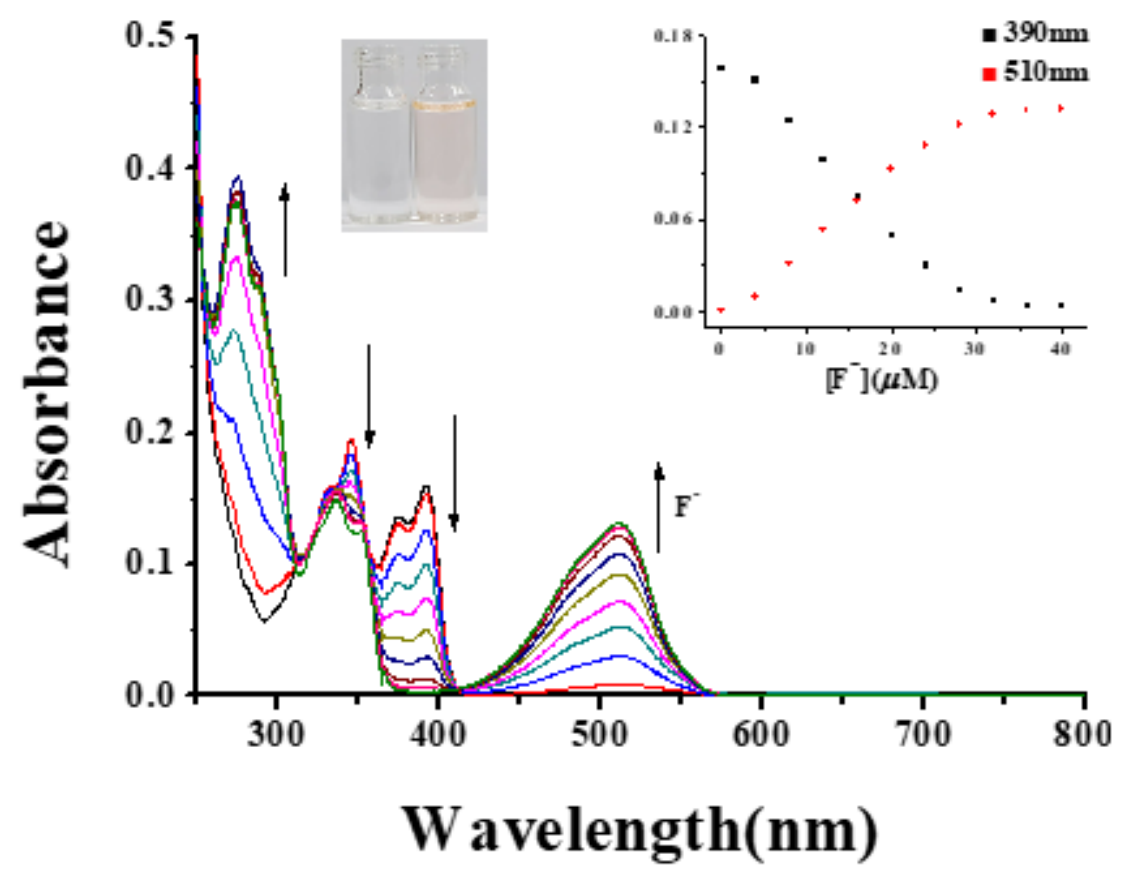

Figure 2

UV-visible titration of probe $1(20 \mu \mathrm{M})$ with TBAF ( $5 \mathrm{mM}, 0$ to 1.8 equiv.) in THF. Inset: color change and plot of absorption changes at 390 and $510 \mathrm{~nm}$ versus TBAF.

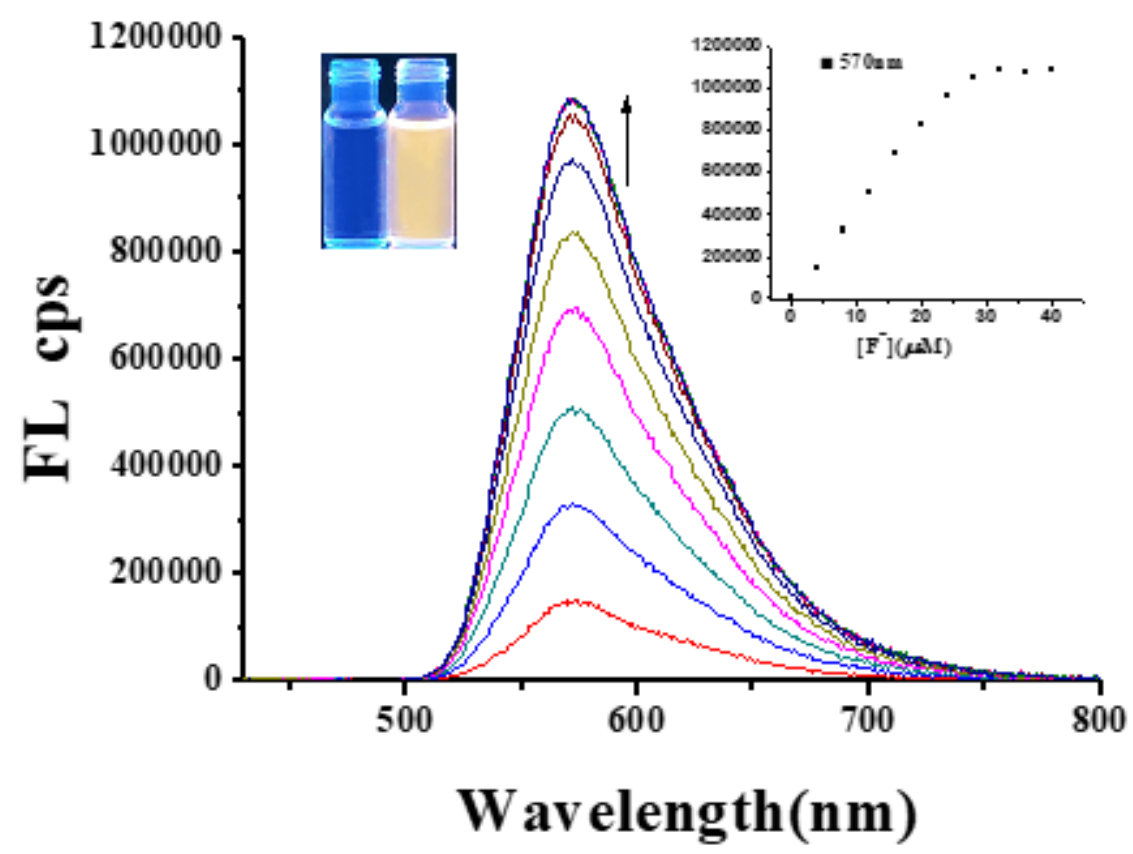

Figure 3

Emission spectra of probe $1(20 \mu \mathrm{M}, \lambda \mathrm{ex}=410 \mathrm{~nm})$ with TBAF ( 0 to 1.6 equiv.) in THF. The inset shows the fluorescence intensity at $570 \mathrm{~nm}$ as a function of TBAF concentrations. 


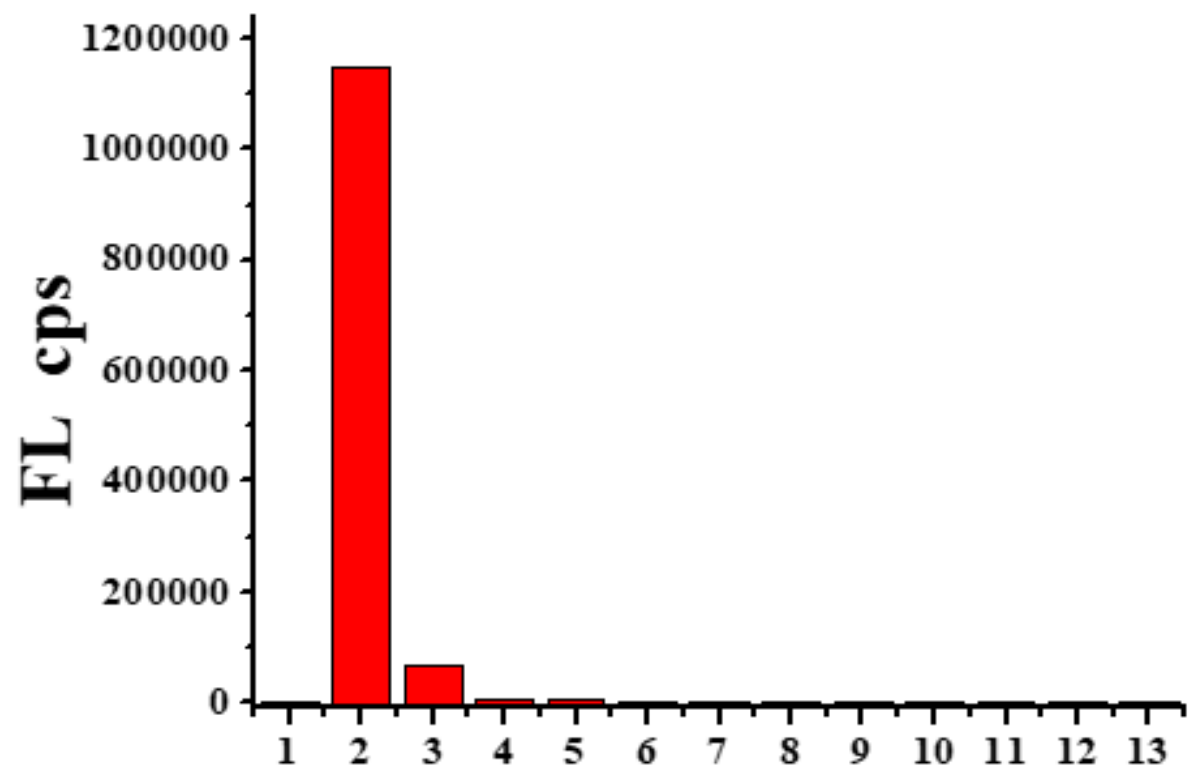

Figure 4

Relative fluorescence changes of probe $1(20 \mu \mathrm{M})$ after treatment with 1.6 equiv. of TBA salt of various anions in THF at $\lambda e x=410 \mathrm{~nm}$ (from left to right: only probe 1, $\mathrm{F}-, \mathrm{CN}-, \mathrm{AcO}-, \mathrm{H} 2 \mathrm{PO} 4-, \mathrm{I}-, \mathrm{Cl}-, \mathrm{NO}-$, HSO4-, $\mathrm{ClO} 4-, \mathrm{BF} 4-, \mathrm{Br}-, \mathrm{OH}-$ ions)

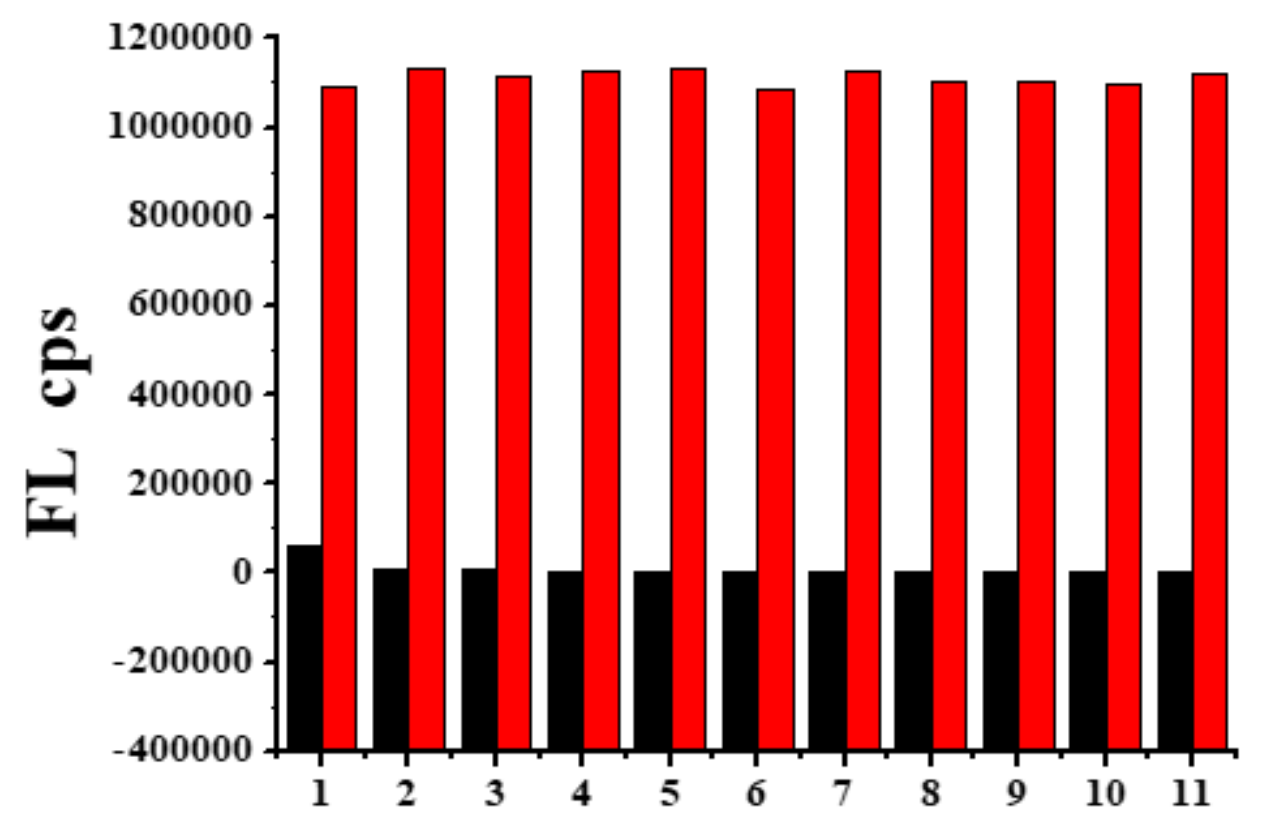

Figure 5

Interference response of probe $1(20 \mu \mathrm{M})$ for $\mathrm{F}$ - in the presence of other anions (1.6 equiv.). The black bars represent the emission at $570 \mathrm{~nm}$ of probe 1 in the presence of 1.6 equiv. of the other anion (from 1 
to 11: $\mathrm{CN}-, \mathrm{AcO}-, \mathrm{H} 2 \mathrm{PO} 4-, \mathrm{I}-, \mathrm{Cl}-, \mathrm{NO} 3-, \mathrm{HSO} 4-, \mathrm{ClO4}-, \mathrm{BF} 4-, \mathrm{Br}-, \mathrm{OH}-)$. The red bars show the change that occurs upon subsequent addition of 1.6 equiv. of $\mathrm{F}$ - to the solution containing probe 1

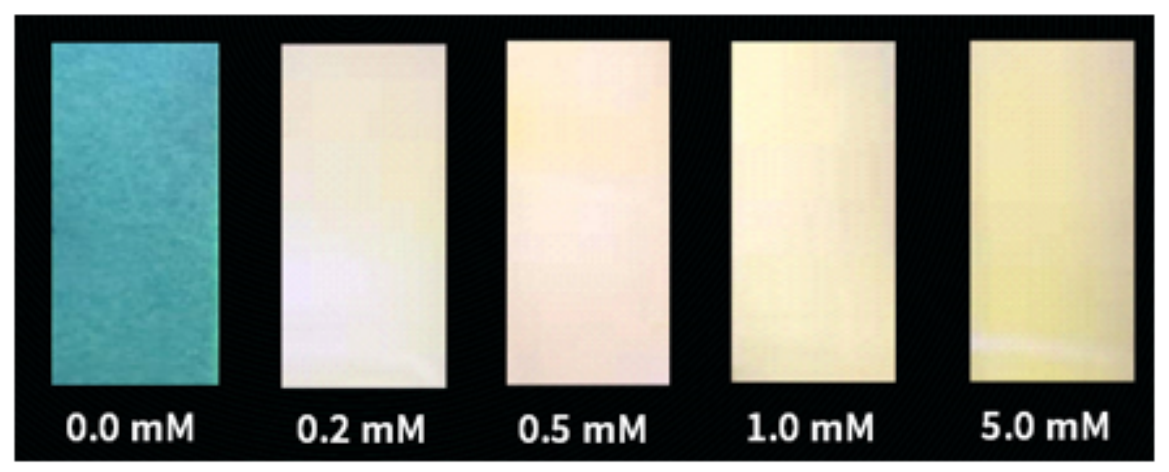

Figure 6

The changes of the probe 1-loaded test papers $(1.0 \mathrm{mM})$ with $\mathrm{F}-$; use hand-held UV lamp to irradiate the test strips at $365 \mathrm{~nm}$.

\section{Supplementary Files}

This is a list of supplementary files associated with this preprint. Click to download.

- supplementary0822.docx

- Scheme1.jpg

- Scheme2.jpg 